\title{
Replacement of dietary fat with palm oil: effect on human serum lipids, lipoproteins and apolipoproteins
}

\author{
BY KALYANA SUNDRAM*, GERARD HORNSTRA $\uparrow$ AND \\ ADRIANA C. v. HOUWELINGEN \\ Department of Human Biology, Limburg University, PO Box 616, 6200 MD Maastricht, \\ The Netherlands \\ AND ARNOLD D. M. KESTER \\ Department of Medical Informatics and Statistics, Limburg University, Postbox 616, \\ 6200 MD Maastricht, The Netherlands
}

(Received 20 May 1991-Accepted 19 November 1991)

\begin{abstract}
Thirty-eight male volunteers participated in a double-blind cross-over trial evaluating the effect of replacing the usual sources of saturated fat in the Dutch diet (animal fats and hydrogenated oils) by palm oil, which is virtually free of cholesterol and trans-fatty acids, on serum lipids, lipoproteins and apolipoproteins. Maximum (about $70 \%$ ) replacement had no significant effect on serum total cholesterol or most lipoprotein fractions, but resulted in an $11 \%$ increase in serum high-density-lipoprotein (HDL) cholesterol relative to the control $\left(P_{2}=0.01\right)$. The palm-oil diet also caused an $8 \%$ decrease in lowdensity-lipoprotein (LDL): $\mathrm{HDL}_{2}+\mathrm{HDL}_{3}$-cholesterol ratio $\left(P_{2}=0.02\right)$ as well as a $9 \%$ decrease in triacylglycerols in the low-density-lipoprotein fractions $\left(P_{2}=0.01\right)$. Palm oil consumption resulted in a $4 \%$ increase in serum apolipoprotein $\mathrm{AI}\left(P_{2}=0.008\right)$ and a $4 \%$ decrease in apolipoprotein $\mathrm{B}\left(P_{2}=0.01\right)$ relative to the control diet; the $\mathrm{B}: \mathrm{Al}$ apolipoprotein ratio was decreased by $8 \%\left(P_{2}<0.0001\right)$. These results were not significantly affected by the different lipoprotein $E$ phenotypes of the volunteers. Although the observed differences were relatively modest, the present study, nonetheless, indicates that dietary palm oil, when replacing a major part of the normal fat content in a Dutch diet, may slightly reduce the lipoprotein- and apolipoprotein-associated cardiovascular risk profiles.
\end{abstract}

Palm oil: Serum lipids: Lipoproteins: Apolipoproteins: Phenotypes: Dietary response

The contributory role of dietary oils and fats in the aetiology of cardiovascular diseases and their ability to influence serum cholesterol levels is well established. Polyunsaturated fatty acids (PUFA) decrease (Spritz \& Mishkel, 1969; Vega et al. 1982), whereas saturated fatty acids (SFA) increase (Keys et al. $1965 a, b$; Pownall et al. 1980; AMA Council on Scientific Affairs, 1983) serum and low-density-lipoprotein (LDL)-cholesterol levels. Recent evidence (Mensink \& Katan, 1989; Ginsberg et al. 1990) also suggests that the substitution of monounsaturated fatty acids (MUFA) for SFA has a similar cholesterol-lowering effect.

Among SFA the potential to raise serum cholesterol levels is variable. Thus, it has repeatedly been shown that stearic acid $\left(C_{18: 0}\right)$ does not raise serum cholesterol (Keys et al. $1965 a, b$; Bonanome \& Grundy, 1988). The major SFA in the human diet, however, is palmitic acid $\left(\mathrm{C}_{16: 0}\right)$ which together with lauric $\left(\mathrm{C}_{12: 0}\right)$ and myristic $\left(\mathrm{C}_{14: 0}\right)$ acids, is considered hypercholesterolaemic (Hashim et al. 1960; Grande, 1962; Hegsted et al. 1965). It should be realized that these types of studies did not take into account the various sources

* Present address: Palm Oil Research Institute of Malaysia (PORIM), PO Box 10620, 50720 Kuala Lumpur, Malaysia.

$\uparrow$ For reprints. 
of these saturates which in the Western hemisphere are chiefly derived from animal fats and hydrogenated vegetable oils. Unfortunately, the consumption of animal fats is associated with increased cholesterol intake, while hydrogenated oils contain considerable amounts of trans-fatty acids which were recently shown to have adverse effects on the serum cholesterol profile (Mensink \& Katan, 1990). Therefore, edible oils rich in saturates, but free from cholesterol and trans-fatty acids, may represent preferred sources of saturates when included in the human diet.

Palm oil contains approximately (g/100 g): palmitic acid 45 , stearic acid 5 , oleic acid 40 and linoleic acid 10, while being virtually free from cholesterol and trans-fatty acids. In addition, palm oil contains a high content of tocotrienols which have been reported to suppress cholesterol synthesis in an animal model (Qureshi et al. 1986). Thus, it is difficult to predict the likely effect of this oil on plasma lipids. In spite of its growing importance as an edible oil (Mielke, 1987), scientific evidence evaluating the role of palm oil in human nutrition is rather limited (Anon, 1987). We, therefore, felt it pertinent to investigate the effect of a diet in which the main fat components have been replaced by palm oil, on the various aspects of the cardiovascular risk profile. In the present paper we report on the effect of a diet in which the main fat components have been replaced by palm oil on serum total-(TC) and lipoprotein-cholesterol and triacylglycerols (TG), and on serum apolipoproteins. Results for other variables of interest, such as blood pressure, coagulation, fibrinolysis and platelet functions will be reported separately.

\section{MATERIALS AND METHODS \\ Experimental design}

The research protocol was approved by the Medical Ethical Committee of the University of Limburg, Maastricht, The Netherlands. Written informed consent was obtained from all participating volunteers.

The study was designed as a double-blind cross-over trial consisting of two periods of 6 weeks each, preceded by a run-in period of 3 weeks and interrupted by a wash-out period of 3 weeks.

To assess the effect of maximal palm oil substitution in a normal Western diet a series of food products, containing palm oil as the major fat source, and a second series of control products, containing the usual fats and oils while excluding palm oil, were prepared and distributed to the volunteers.

During the run-in period all volunteers consumed control products which were formulated to reflect the habitual fat consumption pattern in the Maastricht region of The Netherlands. At the end of this period volunteers entered into the first experimental period, wherein $50 \%$ were assigned the palm-oil products and the remaining $50 \%$ continued to consume the control products. During the wash-out period all volunteers resumed consumption of the control products, whereas on entry into the second experimental period volunteers who consumed the palm oil products in the first period now consumed the control products and vice versa. Maximum care was taken to ensure that both the volunteers and investigators remained unaware of the types of products the volunteers consumed.

\section{Screening, selection and randomization of volunteers}

Male volunteers (120) were recruited from the general population of Maastricht and screened for eligibility 10 weeks before starting the run-in period. Only volunteers fulfilling the following selection criteria were allowed to enter the study: (1) aged between 19 and 45 years, (2) non-obese; body mass index (BMI) $<28 \mathrm{~kg} / \mathrm{m}^{2}$, (3) clinically healthy (no 
Table 1. Characteristics of volunteers at the start of the run-in period (week -3) (Mean values with their standard errors for thirty-eight subjects)

\begin{tabular}{lcccc}
\hline Characteristic & Mean & SEM & Range \\
\hline Age (years) & $35 \cdot 7$ & $0 \cdot 85$ & $19 \cdot 45$ \\
BMI & $23 \cdot 8$ & $0 \cdot 31$ & $20 \cdot 1-26 \cdot 4$ \\
Serum cholesterol (mmol/l) & $5 \cdot 13$ & $0 \cdot 13$ & $3 \cdot 50-6 \cdot 40$ \\
HDL-cholesterol (mmol/l)* & 1.08 & $0 \cdot 04$ & $0 \cdot 70-1 \cdot 80$ \\
Serum triacylglycerols (mmol/l) & 0.99 & $0 \cdot 06$ & $0 \cdot 27-2 \cdot 08$ \\
\hline
\end{tabular}

BMI, body mass index (body-weight $(\mathrm{kg}) /$ height $^{2}(\mathrm{~m})$ ); HDL, high-density-lipoprotein.

* Measured enzymically in serum after heparin-manganese precipitation of very-low-density-and low-densitylipoproteins.

medication, absence of glucose and protein in urine), (4) normotensive (systolic blood pressure between 100 and $140 \mathrm{~mm} \mathrm{Hg}$; diastolic blood pressure between 40 and $90 \mathrm{~mm} \mathrm{Hg}$ ), (5) normolipidaemic (serum TC $<6.8 \mathrm{mmol} / 1$; serum TG $<2.0 \mathrm{mmol} / \mathrm{l}$ ), (6) non-smokers (fewer than seven cigarettes per week), (7) willingness to participate in the study.

A total of fifty-six volunteers were judged eligible and entered the study at -3 weeks (start of the run-in period). The dietary history of each volunteer was recorded by a dietitian and the polyunsaturated : saturated $(P: S)$ fatty acid ratio of the diet was calculated using the BECEL ${ }^{\mathbb{B}}$ computerized program (BECEL ${ }^{\mathbb{B}}$, 1988). Blood was also sampled for serum TC, high-density-lipoprotein-cholesterol (HDL-C) and serum TG on the day of entry into the run-in period.

The final volunteer population (forty persons) was selected on the basis of individual data for $\mathrm{TC}$ as the primary selection criterion with HDL-C and TG as the secondary criteria. Volunteers reporting a $\mathrm{P}: \mathrm{S}$ ratio different from the habitual dietary pattern in The Netherlands were excluded. The selected volunteers were then stratified over two groups of twenty persons on the basis of the previously stated criteria. Of these, one person dropped out of the study because of job commitments requiring travel outside the Maastricht area, and a second volunteer was excluded after he was prescribed medication for treatment of gout by his physician. The entry characteristics of the thirty-eight remaining men who completed the study are given in Table 1 .

Because of optimization in the laboratory, only five volunteers were permitted each day, from Tuesday to Friday. Mondays were excluded to provide a safeguard against unusual activities during the weekend. Within each day, volunteers were subdivided between the two groups in such a manner that equal numbers of volunteers were assigned to the two dietary groups by the end of each second day.

\section{Composition of dietary supplements}

Dietary products contributing a high fat intake in the Dutch diet were identified through a sample dietary survey. Technology permitting, a series of palm-oil-based products was formulated replacing the normal fat component in these products. A second series of the same products, reflecting normal compositions but containing little or no palm oil, was also prepared and used as the control products in this study. Broadly, the products included margarines, frying and bakery fats, snack foods (hamburgers, chicken nuggets, meat croquettes), dairy products (cheese, chocolate milk, ice cream, dairy products), bakery products, and chocolate spread. The characteristics of these products are described elsewhere (Sundram et al. 1990 a). All food products were individually packed in identical packaging material and bar coded, thus offering complete blindness. 
A special 'shop' with appropriate displays of the coded products was manned by dietitians. Volunteers had access to items in the "shop' from Monday to Friday. A computer program was specially designed to keep a complete record of food items handed out to the volunteers. Since each product was bar-coded, the computer automatically decoded the information and only allowed passage of the correct dietary type according to preprogrammed stratification information. Product composition data, previously entered into the computer, enabled the dietitians to monitor continuously for deviations in the P:S ratio of the volunteers' diets. Food products from the 'shop' were made available to the whole family free of charge, in order to optimize compliance.

\section{Compliance measurements}

Since our objective was to investigate the effect of maximum palm oil consumption in a free-living population, we deliberately abstained from any interference with respect to the volunteers' food selection and preparation. However, a strict check on compliance by the volunteers was monitored as follows: all volunteers were instructed to maintain a diary to monitor any occasional deviations from their normal dietary patterns. The diaries were checked at least once weekly by the dietitian. Each week the volunteers were given a list of products that were available to them from the 'shop'. However, if they had purchased any comparable product elsewhere they were asked to indicate dates, brand name and quantity on a 'shadow list'. This enabled compliance to be calculated for each of the products provided, as well as any changes that may have occurred resulting from the use of the 'shadow products'. During the 5th week of each experimental period the volunteers were subjected to a dietary history interview by the dietitian. This permitted calculation of the average nutrient intake during each experimental period and comparison for deviations from their habitual dietary patterns.

During the 4th week of each experimental period volunteers were instructed to collect a duplicate portion of all foods and liquids consumed over a $48 \mathrm{~h}$ period; these were brought to the laboratory for subsequent processing. The duplicate portions were weighed and then homogenized in a food mixer. Approximately $750 \mathrm{~g}$ of the homogenized mixture was collected in lidded tins and frozen at $-20^{\circ}$ until required for analysis.

Fatty acid composition of serum TG was analysed at the end of each experimental period and used as an additional compliance measurement.

\section{Blood sampling procedures}

Volunteers reported to the attending physician at 3-week intervals beginning at -3 weeks and ending on the 15th week. All blood samplings were performed between 08.00 and 12.00 hours under fasting conditions (no food after 22.00 hours the previous evening) and after $24 \mathrm{~h}$ abstinence from alcohol. Body-weights were measured with volunteers wearing minimum indoor clothing and without shoes. The volunteers then took a 10 min rest in a recumbent position. With the volunteers still in a recumbent position, a forearm vein was punctured under minimal stasis using a $19 \mathrm{G}$ butterfly venisystem. After four blood samples had been taken for other measurements (about $50 \mathrm{ml}$ in total, results to be reported elsewhere), two $10 \mathrm{ml}$ samples of blood were collected in two Monovette ${ }^{\mathbb{B}}$ tubes $(051104$; Sarstedt, Numbrecht, Germany). Blood in the first monovette was allowed to clot for $2 \mathrm{~h}$ at room temperature (about $24^{\circ}$ ) and serum prepared for the analysis of TC, HDL-C, TG and the isolation of lipoprotein classes by ultracentrifugation. The second monovette was placed in a water-bath at $37.5^{\circ}$ and blood allowed to clot for precisely $60 \mathrm{~min}$. Serum from this preparation was utilized for the analysis of thromboxane $\mathbf{B}_{2}$ (to be reported elsewhere), serum fatty acids and apolipoproteins. Spare serum was collected whenever possible and stored at $-80^{\circ}$ for later use. This bleeding procedure was carried out during $0,6,9$ and 15 
weeks only. During weeks $-3,3$ and 12 , only $10 \mathrm{ml}$ blood was drawn from the volunteers and used for the analysis of TC, HDL-C and TG. Serum was prepared by centrifugation at $1200 \mathrm{~g}$ and $20^{\circ}$ for $15 \mathrm{~min}$.

\section{Analytical methods}

Lipids and lipoproteins. Isolation of serum lipoprotein classes was performed using a Beckman SW41 rotor in a Beckman L5-65 ultracentrifuge according to a slightly modified method of Terpstra et al. (1981). The isolation procedures were always started within $5 \mathrm{~h}$ of sampling blood from the volunteers.

Briefly, $2.0 \mathrm{ml}$ serum was prestained with $0.2 \mathrm{ml}$ Sudan Black B (S-2380; Sigma, St Louis, MO, USA), in ethylene glycol (822329; Merck, Darmstadt, Germany) and the density $(\rho)$ of this prestained serum was raised to $\rho 201.250 \mathrm{~g} / \mathrm{ml}$ using solid potassium bromide (4905; Merck), sodium chloride (6404; Merck) and sucrose (7651; Merck) in a Beckman Ultraclear ${ }^{(1)}$ (no. 344060) centrifuge tube. The prestained serum was then sequentially layered with salt solutions $\rho 201.225 \mathrm{~g} / \mathrm{ml}(1 \mathrm{l} .42 \mathrm{~g} \mathrm{NaCl}$ and $315.54 \mathrm{~g} \mathrm{KBr} / \mathrm{l})$ followed by salt solution $\rho 201.100 \mathrm{~g} / \mathrm{ml}(11.42 \mathrm{~g} \mathrm{NaCl}$ and $133.48 \mathrm{~g} \mathrm{KBr} / \mathrm{l})$ and overlayered with distilled water. All solutions contained $0 \cdot 112 \mathrm{~g}$ EDTA (disodium salt; 8418; Merck)/l. The layering was performed using a peristaltic pump (10200; LKB, Perpex, Sweden) with controlled displacement speeds that were adjusted so as not to disturb the salt gradients. Tubes were centrifuged for $22 \mathrm{~h}$ at $40000 \mathrm{rev} . / \mathrm{min}$ and $20^{\circ}$. By this technique seven different fractions of prestained lipoproteins were harvested at the following density ranges $(\rho 20 \mathrm{~g} / \mathrm{ml})$ : very-low-density-lipoprotein $(\mathrm{VLDL})<1 \cdot 006$, intermediate-density-lipoprotein (IDL) 1.006-1.019, LDL 1.019-1.055, high-density-lipoprotein (HDL) + atherogenic lipoprotein ( $\mathrm{Lp}(\mathrm{a})$ ) 1.055-1.085, $\mathrm{HDL}_{2} 1.085-1 \cdot 120, \mathrm{HDL}_{3} 1 \cdot 120-1 \cdot 210$ and a bottom fraction (bf) $>1 \cdot 210$.

Customarily $\rho 1.063$ is taken as the demarcation between LDL and HDL. However, this results in the inclusion of appreciable amounts of $\mathrm{Lp}(\mathrm{a})$ into the HDL. By interposing an extra fraction with $\rho 201.055-1.085$, $\mathrm{Lp}(\mathrm{a})$, when present, is largely separated from LDL and $\mathrm{HDL}_{2}$. According to Schmitz \& Assmann (1982), $\mathrm{HDL}_{1}$ floats as a single peak at $\rho$ $1.08-1.09 \mathrm{~g} / 1$. Therefore, our $\rho 201.055-1.085$ fraction would actually consist of both $\mathrm{Lp}(\mathrm{a})$ and $\mathrm{HDL}_{1}$. For convenience, however, this fraction will be termed $\mathrm{HDL}_{1}$. Because $\mathrm{HDL}$ are heterogeneous, several subfractions can be distinguished and the most important of these are $\mathrm{HDL}_{2}$ and $\mathrm{HDL}_{3}$.

Before the actual study, a pilot trial was performed during which serum as well as dummy salt solutions mimicking human serum were used to establish the density ranges of each lipoprotein class using a densitometer. Based on these results, a Perspex mould was constructed which indicated the level of each salt gradient to be layered, as well as the expected distribution ranges of each lipoprotein class in the ultracentrifuge tube. These indicator levels were marked off on each ultracentrifuge tube and served as a guide for harvesting the lipoprotein class by aspiration with a pasteur pipette. Prestaining with Sudan Black $\mathbf{B}$ further helped in maximizing recovery at the correct density ranges.

Cholesterol and TG concentrations in each of these lipoprotein fractions and in serum were determined on an autoanalyser (Cobas Bio; Hoffman-La-Roche, Basel, Switzerland) using commercial enzymic kits (TG, 1086; Roche Diagnostica, Basel, Switzerland; TC, Boehringer Monotest ${ }^{\mathbb{B}}$ cholesterol, Boehringer Mannheim, $\mathrm{GmbH}$ ). Recovery rates of the lipoproteins were calculated as the sum of both cholesterol and TG contents of the fractions and were expressed as a percentage of the serum total cholesterol or triacylglycerols.

The calculated recovery rates from the seven lipoprotein fractions during the entire study (n 153) were 100.12 (SE 0.36) and 95.99 (SE 0.77) \% for cholesterol and TG respectively. Prestaining the serum with Sudan Black B did not interfere with TG analysis. 
Apolipoproteins. Serum apolipoproteins AI, AII and E were determined according to the method of Alvers et al. (1976), while Apo B was evaluated by radial immunodiffusion according to Havekes et al. (1981). Apolipoprotein E phenotypes were measured directly in serum as described by Havekes et al. (1987).

Duplicate portion analysis. Frozen food duplicate portions were thawed and a sample of about $500 \mathrm{~g}$ was freeze-dried. A $20 \mathrm{~g}$ freeze-dried sample was Soxhlet-extracted with light petroleum (b.p. $40-60^{\circ}$ ) for quantification of fat content. Due to a technical error in the laboratory, determinations from six duplicate portions were omitted. A portion of the fat extracted was methylated for fatty acid analysis (Rand et al. 1986) of these duplicate portions. An extensive comparison of fats extracted from the duplicate portions by the Soxhlet method with fats extracted from the duplicate portions by the Bligh \& Dyer (1959) method did not reveal any differences in the fatty acid composition of these duplicate portions. Cholesterol content of the duplicate portions was analysed by gas-liquid chromatography (Bovenkamp \& Katan, 1981).

Fatty acid composition of serum TG. Serum lipids were extracted by the Bligh \& Dyer (1959) method and TG isolated by thin-layer chromatography, scraped, methylated, and the fatty acids were analysed (Rand et al. 1986). For this purpose, serum collected at the end of weeks 6 and 15 were used.

\section{Statistical methods}

Distributions were visually checked for normality and detected outliers were deleted only when clear evidence existed of faulty recording or analytical errors. Results are presented as means with their standard errors (geometric means for log-transformed data). These means are calculated for week 0 , and for the completion of the palm oil and control periods.

Testing the palm oil $v$. control effect was done using the two-sided paired $t$ test modified for the cross-over design as described by Armitage \& Berry (1987). Values for $P\left(P_{2}\right)<0.05$ were considered significant.

Preceding these analyses, tests for treatment $\times$ period interaction were performed (Armitage \& Berry, 1987). If this yielded a significant result at the $5 \%$ level, the comparison of palm oil $v$. control was planned using first-period results only. However, no significant treatment $\times$ period interaction was observed in the present study.

\section{RESULTS}

No major problems were encountered during the study. Acceptance of the food products by the volunteers was excellent, although some of the products were reported by the volunteers to have slightly different sensory properties than normally perceived. Nevertheless, these differences in the sensory properties (taste and texture) did not compromise the consumption of these products as reflected by our dietary records and interviews. Of the forty volunteers enrolled into the study, one person dropped out because of job commitments requiring travel outside the Maastricht area, and a second volunteer was excluded after he was prescribed medication for treatment of gout by his physician.

\section{Dietary composition and compliance}

The results of the dietary history interviews conducted by the dietitians at the start of the run-in period reflect the habitual dietary consumption patterns of the volunteers. Results are shown in Table 2. The results of dietary history interviews conducted during the 5 th week of the palm oil and control periods respectively are also given in Table 2. Mean dietary energy $(\mathrm{MJ} / \mathrm{d})$ and fat energy \% (en \%) were comparable between volunteers 
Table 2. Nutrient intake immediately before (habitual) and during the replacement of dietary fat with palm oil as calculated from repeated dietary histories*

(Mean values with their standard errors for thirty-eight subjects)

\begin{tabular}{|c|c|c|c|c|c|c|c|c|c|}
\hline \multirow[b]{2}{*}{ Variable } & \multicolumn{2}{|c|}{ Habitual } & \multicolumn{2}{|c|}{ Palm oil (PO) } & \multicolumn{2}{|c|}{ Control (CT) } & \multicolumn{2}{|c|}{$(\mathrm{PO}-\mathrm{CT})$} & \multirow{2}{*}{$\begin{array}{c}\text { Statistical } \\
\text { significance } \\
\text { of difference: } \\
P_{2}\end{array}$} \\
\hline & Mean & SEM & Mean & SEM & Mean & SEM & Mean & SEM & \\
\hline Energy $(\mathrm{MJ} / \mathrm{d})$ & $13 \cdot 3$ & 0.43 & $14 \cdot 6$ & 0.44 & $14 \cdot 4$ & $0 \cdot 48$ & $0 \cdot 1$ & $0 \cdot 16$ & NS \\
\hline Fat energy $(\%)$ & $39 \cdot 2$ & $0 \cdot 81$ & $41 \cdot 0$ & $0 \cdot 78$ & $41 \cdot 1$ & 0.69 & $-0 \cdot 1$ & 0.36 & NS \\
\hline Fat energy, PO $(\%)$ & \multicolumn{2}{|c|}{-} & $28 \cdot 7$ & 0.55 & \multicolumn{2}{|c|}{ NIL } & \multicolumn{2}{|c|}{-} & - \\
\hline PUFA (\% energy) & $7 \cdot 0$ & 0.28 & 6.8 & $0 \cdot 20$ & 6.9 & $0 \cdot 21$ & $-0 \cdot 2$ & $0 \cdot 14$ & NS \\
\hline SFA ( $\%$ energy) & $16 \cdot 7$ & 0.39 & $17 \cdot 2$ & $0 \cdot 33$ & $16 \cdot 3$ & $0 \cdot 28$ & 0.9 & 0.21 & $<0.0001$ \\
\hline MUFA (\% energy) & $15 \cdot 5$ & 0.45 & $17 \cdot 1$ & $0 \cdot 38$ & $17 \cdot 8$ & $0 \cdot 37$ & -0.8 & $0 \cdot 23$ & $0 \cdot 001$ \\
\hline $\mathrm{P}: \mathrm{S}$ ratio & 0.40 & 0.02 & $0 \cdot 40$ & 0.01 & 0.43 & 0.01 & -0.04 & 0.01 & 0.001 \\
\hline
\end{tabular}

PUFA, polyunsaturated fatty acids; SFA, saturated fatty acids; MUFA, monounsaturated fatty acids; P:S, polyunsaturated: saturated fatty acids; NS, not significant.

* For details of subjects and procedures, see Table 1 and pp. 678-682.

consuming the palm-oil and control diets, but were increased in comparison with the habitual diet. However, this did not result in significant changes in body-weight during the study (palm oil -0.1 (SE 0.14) kg, control -0.3 (SE 0.18) kg; within-group and betweengroups differences were not significant). Differences in the energy derived from the various fatty acids were also evident from these dietary interviews. Palm-oil consumption resulted in a higher intake of energy from the saturates in comparison with both the control and habitual diets $\left(P_{2}<0.0001\right)$. A significant difference in the energy derived from polyunsaturates was, however, not evident. Subsequently, the $\mathrm{P}: \mathrm{S}$ ratio of the diet during the palm-oil period was significantly lower $\left(P_{2}=0.001\right)$ than that of the diets during the control and run-in periods.

From duplicate-portion analysis it appeared that during the palm-oil period the diet contained 120 (SE 5.8) g fat/d, which was equivalent to 40.5 (SE 1.4 ) $\%$ of the daily energy intake of which 28.7 (SE 0.55 ) en \% was derived directly from palm oil. A slightly lower fat consumption (113 (SE 6.8) g/d ) was observed during the control period, accounting for 39.4 (SE 1.5$) \%$ of the daily energy intake. These differences in fat content and fat-en $\%$ were not significant between dietary treatments. Cholesterol intake $(\mathrm{mg} / \mathrm{d})$ determined from these double portions was significantly lower $\left(P_{2}=0.004\right)$ during the palm-oil diet (193 (SE 15); $n$ 35) than the control diet (259 (SE 24); $n$ 34).

Energy (MJ) estimated from the dietary histories was higher than that determined from the duplicate portions during both dietary periods. There was a poor correlation between the two methods for the estimation of daily energy intake. However, when fat-en $\%$ was considered, the values determined by the dietary histories ( $X 40.23$ (SE 0.52$)$ en \%) and the duplicate portions $(Y 39.92$ (SE 1.01) en \%) were correlated significantly: $Y=16.80+$ $0.575 X, r 0.30, n 77, P=0.008)$.

Fatty acid composition of the duplicate portions (Table 3 ) collected over a 48 h period showed significant differences between the palm-oil and control diets. Indeed all fatty acids except $\mathrm{C}_{12: 0}, \mathrm{C}_{18: 1(n-9)}, \mathrm{C}_{20: 0}$ and the minor fatty acids (less than $0 \cdot 1 \mathrm{~g} / 100 \mathrm{~g}$ total fatty acids) were significantly different between treatments. In these duplicate-portion analyses, neither the sum of the PUFA nor the MUFA were significantly different between treatments. However, the palm-oil diet resulted in a higher SFA content $\left(P_{2}<0.0001\right)$ than 
Table 3. Fatty acid composition ( $\mathrm{g} / 100 \mathrm{~g}$ total fatty acids) of lipids extracted from duplicate portions collected over $48 \mathrm{~h}$ period for subjects given the control diet or the diet in which dietary fat had been replaced by palm oil*

(Mean values with their standard errors; no. of subjects in parentheses)

\begin{tabular}{|c|c|c|c|c|c|}
\hline \multirow[b]{2}{*}{ Fatty acid } & \multicolumn{2}{|c|}{ Palm oil (36) } & \multicolumn{2}{|c|}{ Control (38) } & \multirow{2}{*}{$\begin{array}{c}\text { Statistical } \\
\text { significance } \\
\text { of difference: } \\
P_{2}\end{array}$} \\
\hline & Mean & SEM & Mean & SEM & \\
\hline $10: 0$ & $0 \cdot 2$ & 0.02 & $0 \cdot 4$ & 0.04 & $<0.0001$ \\
\hline $12: 0$ & 1.8 & $0-21$ & $2 \cdot 0$ & $0 \cdot 21$ & NS \\
\hline $14: 0$ & $2 \cdot 4$ & $0 \cdot 11$ & $4 \cdot 7$ & 0.25 & $<0.0001$ \\
\hline $15: 0$ & $0 \cdot 1$ & $0 \cdot 02$ & 0.4 & 0.03 & $<0.0001$ \\
\hline $16: 0$ & $28 \cdot 6$ & 0.67 & $20 \cdot 8$ & 0.64 & $<0.0001$ \\
\hline $16: 1(n-7)$ & $1 \cdot 4$ & 0.08 & $2 \cdot 7$ & $0 \cdot 12$ & $<0.0001$ \\
\hline $17: 0$ & $0-3$ & 0.01 & 0.6 & 0.03 & $<0.0001$ \\
\hline $18: 0$ & $6 \cdot 9$ & 0.17 & 8.6 & $0 \cdot 20$ & $<0.0001$ \\
\hline $18: 1(n-9)$ & $38 \cdot 7$ & 0.37 & 37.2 & 0.66 & NS \\
\hline $18: 2(n-6)$ & $14 \cdot 3$ & 0.59 & $12 \cdot 7$ & 0.60 & 0.02 \\
\hline $20: 0$ & 0.5 & $0-03$ & 0.6 & 0.06 & NS \\
\hline $18: 3(n-3)$ & $2 \cdot 0$ & 0.09 & $2 \cdot 6$ & 0.14 & $<0.0001$ \\
\hline $20: 1(n-9)$ & 0.8 & 0.05 & 1.8 & $0 \cdot 13$ & $<0.0001$ \\
\hline $22: 0$ & 0.2 & 0.03 & 0.4 & 0.03 & $<0.0001$ \\
\hline $22: 1(n-9)$ & 0.2 & 0.03 & $0 \cdot 6$ & 0.07 & $<0.0001$ \\
\hline SFA & $41 \cdot 1$ & $0 \cdot 61$ & 38.6 & 0.88 & 0.002 \\
\hline PUFA & $16 \cdot 4$ & 0.63 & 15.4 & 0.67 & NS \\
\hline MUFA & $41 \cdot 1$ & 0.44 & $42 \cdot 3$ & 0.56 & NS \\
\hline P:S ratio & $0 \cdot 4$ & 0.02 & 0.4 & 0.03 & NS \\
\hline$(n-6):(n-3)$ ratio & $7 \cdot 4$ & $0 \cdot 37$ & $5 \cdot 1$ & 0.28 & $<0.0001$ \\
\hline
\end{tabular}

SFA, saturated fatty acids; PUFA, polyunsaturated fatty acids; MUFA, monounsaturated fatty acids; P:S, polyunsaturated: saturated fatty acids; NS, not significant.

* For details of subjects and procedures, see Table 1 and pp. 678-682.

the control diet. Nevertheless, these shifts in the different fatty acid classes did not cause significant differences in the calculated P:S ratio. A higher $(n-6):(n-3)$ fatty acid ratio was evident on the palm-oil diet.

Fatty acid composition of serum TG is reported in Table 4. Diet-induced changes in these fatty acid compositions were evident. Both palmitic $\left(P_{2}<0.0001\right)$ and oleic $\left(P_{2}=\right.$ 0.02 ) acids in serum TG were significantly elevated due to the palm-oil diet compared with the control diet. On the other hand, the palm-oil diet caused significant reductions in the serum TG fatty acids, 16:1 $(n-7), 17: 0,18: 2(n-9), 18: 3(n-3), 20: 1(n-9)$ and $21: 0$, relative to the control diet. The sum of serum TG-SFA was significantly increased $\left(P_{2}=\right.$ $0.01)$ on the palm-oil diet in comparison with the control diet, whereas no significance was detected in the sum of the PUFA, although a tendency of the PUFA to be elevated after the control diet was noted.

\section{Serum TC, HDL-C and TG}

Initial values (week zero) of the volunteers enrolled in the study ( $n 38)$ were as follows (mmol/l); serum TC 5.11 (SE 0.11), HDL-C 1.13 (SE 0.03), serum TG 1.028 (SE 0.056). For these variables there was hardly any diet-induced difference between the palm-oil and control diets respectively: serum TC (4.94 (SE 0.12), 4.92 (SE 0.12); HDL-C (1.15 (SE 0.04), $1 \cdot 11$ (SE 0.04); serum TG $(0.962$ (SE 0.055), 1.007 (SE 0.056)). 
Table 4. Fatty acid composition ( $\mathrm{g} / 100 \mathrm{~g}$ total fatty acids) of serum triacylglycerols after dietary treatments for subjects given the control diet or the diet in which dietary fat had been replaced by palm oil*

(Mean values with their standard errors; no. of subjects in parentheses)

\begin{tabular}{|c|c|c|c|c|c|}
\hline \multirow[b]{2}{*}{ Fatty acid } & \multicolumn{2}{|c|}{ Palm oil (38) } & \multicolumn{2}{|c|}{ Control (38)c } & \multirow{2}{*}{$\begin{array}{c}\text { Statistical } \\
\text { significance } \\
\text { of difference: } \\
P_{2}\end{array}$} \\
\hline & Mean & SEM & Mean & SEM & \\
\hline $14: 0$ & 1.0 & 0.08 & $1 \cdot 3$ & $0 \cdot 13$ & 0.01 \\
\hline $16: 0$ & $23 \cdot 2$ & 0.28 & 20.9 & 0.42 & $<0.0001$ \\
\hline $16: 1(n-7)$ & 4.5 & 0.17 & $5 \cdot 4$ & 0.17 & $<00001$ \\
\hline $17: 0$ & 0.6 & 0.05 & 0.8 & 0.05 & 0.0007 \\
\hline $18: 0$ & $3 \cdot 2$ & $0 \cdot 17$ & $3 \cdot 3$ & 0.14 & NS \\
\hline $18: 1(n-9)$ & $41 \cdot 4$ & 0.38 & $40 \cdot 1$ & 0.46 & 0.02 \\
\hline $18: 2(n-9)$ & $0 \cdot 3$ & 0.06 & 0.8 & 0.08 & $<0.0001$ \\
\hline $18: 2(n-6)$ & 17.9 & 0.51 & $18 \cdot 2$ & 0.69 & NS \\
\hline $18: 3(n-6)$ & 0.4 & 0.04 & 0.5 & 0.05 & NS \\
\hline $20: 0$ & $0 \cdot 1$ & 0.02 & $0 \cdot 2$ & 0.03 & NS \\
\hline $18: 3(n-3)$ & 1.7 & 0.06 & $2 \cdot 1$ & 0.09 & $<0.0001$ \\
\hline $20: 1(n-9)$ & 0.5 & 0.02 & 0.7 & 0.05 & 0.0005 \\
\hline $21: 0$ & 0.2 & 0.08 & $0 \cdot 4$ & 0.12 & 0.04 \\
\hline $20: 3(n-9)$ & 0.2 & 0.05 & $0 \cdot 3$ & 0.06 & NS \\
\hline $20: 3(n-6)$ & 0.2 & 0.02 & $0 \cdot 2$ & 0.03 & NS \\
\hline $20: 4(n-6)$ & $1 \cdot 2$ & 0.06 & $1 \cdot 2$ & 0.05 & NS \\
\hline $20: 5(n-3)$ & $0 \cdot 3$ & 0.04 & $0 \cdot 3$ & 0.03 & NS \\
\hline $24: 0$ & $0 \cdot 1$ & 0.06 & $0 \cdot 1$ & 0.06 & NS \\
\hline $22: 4(n-6)$ & 0.2 & 0.03 & $0 \cdot 2$ & 0.02 & NS \\
\hline $22: 5(n-3) \div$ & $0 \cdot 4$ & 0.03 & 0.5 & 0.03 & NS \\
\hline $22: 6(n-3)$ & $0 \cdot 6$ & 0.06 & $0-7$ & 0.05 & NS \\
\hline SFA & $28 \cdot 5$ & $0 \cdot 37$ & $27 \cdot 1$ & $0 \cdot 48$ & 0.01 \\
\hline PUFA & 23.6 & 0.60 & $25 \cdot 0$ & $0 \cdot 80$ & NS \\
\hline MUFA & 46.4 & 0.41 & $46 \cdot 2$ & $0 \cdot 52$ & NS \\
\hline$(n-6):(n-3)$ ratio & $8 \cdot 4$ & 0.29 & $7 \cdot 2$ & $0 \cdot 33$ & 0.004 \\
\hline SCFA & 1.0 & 0.08 & $1 \cdot 4$ & $0 \cdot 15$ & 0.01 \\
\hline
\end{tabular}

SFA, saturated fatty acids; PUFA, polyunsaturated fatty acids; MUFA, monounsaturated fatty acids; SCFA, shorter-chain fatty acids $(10: 0+12: 0+14: 0)$; NS, not significant.

* For details of subjects and procedures, see Table 1 and pp. 678-682.

$\dagger$ May contain some $24: 2(n-6)$ fatty acid.

\section{Cholesterol and TG contents of serum lipoproteins}

Cholesterol values for serum and lipoprotein fractions at the completion of the palm-oil and control treatments are given in Table 5. For most of the lipoprotein fractions, cholesterol levels were essentially similar after the palm-oil and control treatments. However, palm-oil consumption resulted in a significant increase $\left(9.7 \% ; P_{2}=0.01\right)$ in the $\mathrm{HDL}_{2}-\mathrm{C}$ compared with the control treatment.

The ratios of cholesterol in various lipoprotein classes were calculated to provide a better indicator of the dietary effect (Table 6). Compared with the control treatment, the palmoil diet caused a significant reduction $\left(7 \cdot 2 \% ; P_{2}=0.02\right)$ in the LDL-cholesterol (LDLC): $\mathrm{HDL}_{2}+\mathrm{HDL}_{3}\left(\mathrm{HDL}_{2+3}\right)$-C ratio. A similar statistically-significant reduction $(7 \cdot 6 \%$; $P_{2}=0.02$ ) in the IDL-cholesterol (IDL-C) + LDL-C: $\mathrm{HDL}_{2+3}-\mathrm{C}$ ratio was again evident on the palm-oil diet compared with the control diet. The $\mathrm{TC}: \mathrm{HDL}_{2+3} \mathrm{C}$ ratio, although lower in the palm-oil diet than the control diet, did not attain significance. 
Table 5. Serum total (TC) and lipoprotein-cholesterol levels (mmol/l) before and after dietary treatments for subjects given the control diet or the diet in which dietary fat had been replaced by palm oil*

(Mean values with their standard errors; no. of subjects in parentheses)

\begin{tabular}{|c|c|c|c|c|c|c|c|c|c|}
\hline & \multicolumn{2}{|c|}{$\begin{array}{c}\text { Initial } \\
(38)\end{array}$} & \multicolumn{2}{|c|}{$\begin{array}{l}\text { Palm oil (PO) } \\
(37)\end{array}$} & \multicolumn{2}{|c|}{$\begin{array}{c}\text { Control (CT) } \\
(38)\end{array}$} & \multicolumn{2}{|c|}{$\begin{array}{c}(\mathrm{PO}-\mathrm{CT}) \\
(37)\end{array}$} & \multirow{2}{*}{$\begin{array}{c}\text { Statistical } \\
\text { significance } \\
\text { of difference } \\
P_{2}\end{array}$} \\
\hline & Mean & SEM & Mean & SEM & Mean & SEM & Mean & SEM & \\
\hline Serum TC & $5 \cdot 11$ & $0 \cdot 11$ & 4.94 & 0.11 & $4 \cdot 92$ & $0 \cdot 12$ & $0 \cdot 02$ & $0 \cdot 10$ & NS \\
\hline VLDL & 0.42 & 0.03 & $0 \cdot 36$ & 0.03 & $0 \cdot 38$ & 0.03 & -0.03 & 0.03 & NS \\
\hline IDL & 0.29 & 0.03 & 0.23 & 0.02 & 0.25 & 0.02 & -0.02 & $0-02$ & NS \\
\hline LDL & $3 \cdot 04$ & $0 \cdot 10$ & $2 \cdot 84$ & $0 \cdot 10$ & $2 \cdot 91$ & $0 \cdot 11$ & $-0 \cdot 10$ & 0.08 & NS \\
\hline $\mathrm{HDL}_{1}$ & 0.20 & 0.02 & $0 \cdot 19$ & 0.01 & 0.17 & 0.01 & 0.01 & 0.01 & NS \\
\hline $\mathrm{HDL}_{2}$ & 0.31 & 0.02 & $0 \cdot 31$ & 0.02 & $0 \cdot 28$ & 0.02 & 0.03 & 0.01 & 0.01 \\
\hline $\mathrm{HDL}_{3}$ & 0.83 & 0.02 & $0 \cdot 81$ & 0.02 & 0.78 & $0 \cdot 02$ & $0 \cdot 03$ & 002 & NS \\
\hline $\mathrm{Bf}$ & $0 \cdot 19$ & 0.01 & 0.17 & 0.01 & $0 \cdot 16$ & 0.01 & $0 \cdot 01$ & $0 \cdot 01$ & NS \\
\hline Recovery $(\%)$ & $102 \cdot 9$ & 0.89 & $98 \cdot 83$ & 0.51 & $100 \cdot 25$ & 0.67 & $-1 \cdot 37$ & 0.87 & NS \\
\hline
\end{tabular}

VLDL, very-low-density-lipoprotein; IDL, intermediate-density-lipoprotein; LDL, low-density-lipoprotein; HDL, high-density-lipoprotein; Bf, bottom fraction; NS, not significant.

* For details of subjects and procedures, see Table 1 and pp. 678-682.

Table 6. Effect of replacement of dietary fat with palm oil on the cholesterol ratios of serum $(T C)$ and lipoprotein fractions of volunteers*

(Mean values with their standard errors; no. of subjects in parentheses)

\begin{tabular}{|c|c|c|c|c|c|}
\hline & \multicolumn{2}{|c|}{$\begin{array}{l}\text { Palm oil } \\
(37)\end{array}$} & \multicolumn{2}{|c|}{$\begin{array}{c}\text { Control } \\
(38)\end{array}$} & \multirow{2}{*}{$\begin{array}{c}\text { Statistical } \\
\text { significance } \\
\text { of difference } \\
P_{2}\end{array}$} \\
\hline & Mean & SEM & Mean & SEM & \\
\hline $\mathrm{LDL}:\left(\mathrm{HDL}_{2}+\mathrm{HDL}_{3}\right)$ & 2.69 & $0 \cdot 16$ & $2 \cdot 90$ & $0 \cdot 17$ & $0 \cdot 02$ \\
\hline$(\mathrm{IDL}+\mathrm{LDL}):\left(\mathrm{HDL}_{2}+\mathrm{HDL}_{3}\right)$ & $2 \cdot 91$ & $0 \cdot 17$ & $3 \cdot 15$ & 0.18 & 0.02 \\
\hline $\mathrm{TC}:\left(\mathrm{HDL}_{2}+\mathrm{HDL}_{3}\right)$ & 4.67 & $0 \cdot 22$ & 4.87 & $0 \cdot 21$ & NS \\
\hline $\mathrm{HDL}_{2}: \mathrm{HDL}_{3}$ & $0 \cdot 38$ & 0.03 & $0 \cdot 36$ & 0.02 & NS \\
\hline $\mathrm{HDL}_{2}: \mathrm{LDL}^{3}$ & $0 \cdot 120$ & 0.012 & $0 \cdot 105$ & $0 \cdot 010$ & $0 \cdot 01$ \\
\hline
\end{tabular}

LDL, low-density-lipoprotein; HDL, high-density-lipoprotein; IDL, intermediate-density-lipoprotein; NS, not significant.

* For details of subjects and treatments, see Table 1 and pp. 678-682.

TG values for serum and lipoprotein fractions at the end of the palm-oil and control treatments are represented in Table 7 . Compared with the control treatment, the palm-oil diet showed a tendency to lower $\mathrm{TG}$ in all lipoprotein fractions except the bf. In comparison with the observed values at the completion of the control treatment, the reduction of TG after the palm-oil treatment was significant $\left(9.3 \% ; P_{2}=0.01\right)$ in the LDL fraction.

\section{Serum apolipoproteins}

Serum apolipoproteins at week zero (initial values) and after the dietary periods are given in Table 8. After volunteers consumed the palm-oil diet, apolipoprotein AI was significantly higher $\left(P_{2}=0.008\right)$ whereas the apolipoprotein B was significantly lower $\left(P_{2}=0.01\right)$ relative to the values after the control diet. A diet-induced effect was not evident on 
Table 7. Effect of replacement of dietary fat with palm oil on serum and lipoprotein triacylglycerols $(\mathrm{mmol} / \mathrm{l})$ of volunteers*

(Mean values with their standard errors; no. of subjects in parentheses)

\begin{tabular}{|c|c|c|c|c|c|c|c|c|c|}
\hline & \multicolumn{2}{|c|}{$\begin{array}{c}\text { Initial } \\
(38)\end{array}$} & \multicolumn{2}{|c|}{$\begin{array}{c}\text { Palm oil (PO) } \\
\text { (37) }\end{array}$} & \multicolumn{2}{|c|}{$\begin{array}{c}\text { Control (CT) } \\
(38)\end{array}$} & \multicolumn{2}{|c|}{$(\mathrm{PO}-\mathrm{CT})$} & \multirow{2}{*}{$\begin{array}{c}\text { Statistical } \\
\text { significance } \\
\text { of difference } \\
P_{2}\end{array}$} \\
\hline & Mean & SEM & Mean & SEM & Mean & SEM & Mean & SEM & \\
\hline Serum & 1.028 & 0.056 & 0.962 & 0.055 & 1.007 & $0 \cdot 056$ & $-0 \cdot 046$ & $0 \cdot 047$ & NS \\
\hline VLDL & 0.647 & 0.047 & 0.585 & 0.049 & 0.606 & $0 \cdot 046$ & -0.031 & $0 \cdot 042$ & NS \\
\hline IDL & $0-060$ & 0.004 & 0.051 & 0.003 & 0.065 & 0.009 & -0.015 & 0.008 & NS \\
\hline LDL & 0.159 & 0.008 & 0.137 & $0 \cdot 005$ & $0 \cdot 151$ & 0.007 & -0.012 & 0.005 & 0.01 \\
\hline $\mathrm{HDL}_{1}$ & 0.015 & 0.002 & $0 \cdot 013$ & 0.001 & 0.014 & 0.001 & -0.001 & 0.001 & NS \\
\hline $\mathrm{HDL}_{2}$ & 0.025 & 0.002 & 0.023 & 0.002 & 0.024 & $0 \cdot 002$ & -0.001 & 0.002 & NS \\
\hline $\mathrm{HDL}_{3}$ & 0.070 & 0.004 & $0 \cdot 068$ & 0.003 & 0.070 & 0.004 & -0.002 & $0 \cdot 004$ & NS \\
\hline $\mathrm{Bf}$ & 0.037 & 0.003 & 0.046 & 0.003 & 0.040 & $0 \cdot 002$ & 0.005 & 0.003 & NS \\
\hline Recovery (\%) & $98 \cdot 49$ & 1.06 & $94 \cdot 85$ & 0.61 & $95 \cdot 71$ & 0.76 & $-0 \cdot 70$ & $0 \cdot 83$ & NS \\
\hline
\end{tabular}

VLDL, very-low-density-lipoprotein; IDL, intermediate-density-lipoprotein; LDL, low-density-lipoprotein; HDL, high-density-lipoprotein; Bf, bottom fraction; NS, not significant.

* For details of subjects and procedures, see Table 1 and pp. 678-682.

Table 8. Effect of replacement of dietary fat with palm oil on serum apolipoproteins $(\mathrm{g} / \mathrm{l})$ and their calculated ratios for volunteers*

(Mean values with their standard errors; no. of subjects in parentheses)

\begin{tabular}{|c|c|c|c|c|c|c|c|c|c|}
\hline & \multicolumn{2}{|c|}{$\begin{array}{c}\text { Initial } \\
(38)\end{array}$} & \multicolumn{2}{|c|}{$\begin{array}{c}\text { Palm oil (PO) } \\
(37)\end{array}$} & \multicolumn{2}{|c|}{$\begin{array}{c}\text { Control (CT) } \\
(38)\end{array}$} & \multicolumn{2}{|c|}{$\begin{array}{c}(\mathrm{PO}-\mathrm{CT}) \\
(37)\end{array}$} & \multirow{2}{*}{$\begin{array}{c}\text { Statistical } \\
\text { significance } \\
\text { of difference } \\
P_{2}\end{array}$} \\
\hline & Mean & SEM & Mean & SEM & Mean & SEM & Mean & SEM & \\
\hline Apo AI & 1.40 & $0 \cdot 22$ & 1.45 & $0 \cdot 26$ & $1 \cdot 40$ & $0 \cdot 26$ & 0.05 & 0.18 & 0.008 \\
\hline Apo All & 0.63 & $0 \cdot 14$ & 0.64 & $0 \cdot 12$ & 0.64 & $0 \cdot 013$ & 0 & 0.7 & NS \\
\hline Apo $B$ & 0.95 & $0 \cdot 27$ & 0.94 & $0 \cdot 30$ & 0.99 & $0 \cdot 29$ & -0.04 & $0 \cdot 20$ & 0.01 \\
\hline Apo E $(\%)$ & 1160 & $2 \cdot 8$ & $112 \cdot 0$ & $2 \cdot 6$ & $116 \cdot 0$ & $3 \cdot 2$ & $-4 \cdot 0$ & $2 \cdot 4$ & NS \\
\hline Apo B:Apo AI & 0.69 & $0 \cdot 024$ & 0.66 & $0 \cdot 027$ & 0.72 & $0 \cdot 028$ & -0.06 & $0 \cdot 014$ & $<0.0001$ \\
\hline Apo B: Apo $E$ & $0 \cdot 83$ & $0 \cdot 024$ & $0 \cdot 85$ & 0.026 & 0.86 & 0.026 & -0.01 & 0.026 & NS \\
\hline LDL-C:Apo B & 1.25 & 0.027 & $1 \cdot 16$ & $0 \cdot 026$ & $1 \cdot 14$ & $0 \cdot 023$ & 0.01 & 0.027 & NS \\
\hline HDL-C:Apo AI & $0 \cdot 31$ & 0.007 & $0 \cdot 30$ & 0.008 & 0.29 & $0 \cdot 006$ & 0.01 & 0.008 & NS \\
\hline
\end{tabular}

LDL-C, low-density-lipoprotein-cholesterol; HDL-C, high-density-lipoprotein-cholesterol: NS, not significant.

* For details of subjects and procedures, see Table 1 and pp. 678-682.

apolipoproteins AII and E levels. As a consequence of these significant changes in the apolipoproteins, the apolipoprotein B:AI ratio was significantly decreased $\left(P_{2}<0.0001\right)$ when compared with the control diet. The apolipoprotein B:E ratio was, however, not significantly affected by the dietary treatments.

The apo E phenotypes of our subjects were also characterized in an attempt to examine the effect of phenotype on changes induced by our test and control diets. Of the thirty-eight volunteers in the present study, eleven had the apo E $3 / 2$ phenotype, twenty-two the apo E $3 / 3$ phenotype and the remaining five had the apo E 4/3 phenotype. Serum and lipoprotein cholesterol at the end of week zero (initial values) were re-assigned according to the three phenotypes (Table 9). Differences between phenotypes were tested using the 
Table 9. Initial levels of serum (TC) and lipoprotein-cholesterol ( $\mathrm{mmol} / \mathrm{l})$ of the volunteers* according to apo E phenotypes ( $p h E)$

(Mean values with their standard errors; no. of subjects in parentheses)

\begin{tabular}{|c|c|c|c|c|c|c|}
\hline & \multicolumn{2}{|c|}{ phE 3/3 (22) } & \multicolumn{2}{|c|}{ phE $3 / 2(11)$} & \multicolumn{2}{|c|}{$\operatorname{phE~4/3(5)~}$} \\
\hline & Mean & SEM & Mean & SEM & Mean & SEM \\
\hline $\mathrm{TC}$ & $5 \cdot 19$ & $0 \cdot 14$ & $4 \cdot 70^{\mathrm{a}}$ & 0.20 & $5 \cdot 64^{3}$ & $0 \cdot 15$ \\
\hline VLDL & 0.45 & 0.04 & 0.41 & 0.04 & $0 \cdot 36$ & 0.09 \\
\hline IDL & $0 \cdot 29$ & 0.04 & $0 \cdot 31$ & $0 \cdot 04$ & $0 \cdot 26$ & 0.03 \\
\hline $\mathrm{LDL}$ & $3.08^{b}$ & 0.13 & $2.65^{\mathrm{v}}$ & 0.12 & $3.71^{\mathrm{b}, \mathrm{c}}$ & 0.08 \\
\hline $\mathrm{HDL}_{1}$ & $0 \cdot 22$ & 0.02 & $0 \cdot 18$ & 0.02 & $0 \cdot 14$ & 0.02 \\
\hline $\mathrm{HDL}_{2}$ & $0 \cdot 34$ & 0.03 & $0 \cdot 30$ & 0.03 & $0 \cdot 24$ & 0.03 \\
\hline $\mathrm{HDL}_{3}$ & $0 \cdot 86$ & 0.02 & 0.75 & 0.06 & 0.84 & 0.08 \\
\hline $\mathrm{Bf}$ & $0 \cdot 19$ & 0.01 & 0.20 & 0.02 & 0.23 & $0 \cdot 04$ \\
\hline
\end{tabular}

a.b' Mean values with the same superscript letter were significantly different (Bonferroni adjusted $t$ test): ${ }^{\text {a. }}{ }^{\mathrm{b}} P_{2}=0.03 ;{ }^{c} P_{2}=0.0009$.

VLDL, very-low-density-lipoprotein; IDL, intermediate-density-lipoprotein; LDL, low-density-lipoprotein; HDL, high-density-lipoprotein; Bf, bottom fraction.

* For details, see Table 1 and pp. 678-682.

Bonferroni-adjusted $t$ test. TC was lowest in phE $3 / 2$ and highest in phE $4 / 3\left(P_{2}=0 \cdot 03\right)$. However, serum TC did not differ significantly between phenotypes $3 / 3$ and $4 / 3$ nor between $3 / 3$ and 3/2. Similarly, LDL-C was lowest in phE $3 / 2$, intermediate in phE $3 / 3$ and highest in phE 4/3. These differences in LDL-C were significant for $3 / 2 v .4 / 3\left(P_{2}=\right.$ $0.0009)$ and $3 / 3$ v. $4 / 3\left(P_{2}=0.03\right)$. An extensive analysis of all data failed to establish any relationship between these apo $E$ phenotypes and the effect of dietary treatments.

\section{DISCUSSION}

Through our product development techniques we were able to maximize the use of palm oil in a European type of diet. This maximization was achieved without major changes in the normal dietary consumption patterns of the volunteers with an adequate acceptance of the products.

Palm oil has a P:S ratio of 0.2 with an almost equal distribution of SFA and unsaturated fatty acids (Sundram et al. 1990 b). In the present study, replacement with palm oil, calculated on the basis of several compliance indicators, was almost $70 \%$ of the daily fat intake during the experimental period. In spite of this unusually high replacement with palm oil, the overall change in dietary $P: S$ ratio was very nominal, with the $P: S$ ratio varying between 0.43 during the habitual diet and 0.40 during the palm oil period. This $P: S$ ratio is well within the range normally reported for The Netherlands (Ministry of Welfare, Health and Cultural Affairs and Ministry of Agriculture and Fisheries, The Netherlands, 1988). However, the percentage energy from $C_{14: 0}$ was halved $(1.92 v .0 .98)$ even as the percentage energy from $C_{16: 0}$ was increased from 8.5 to $11 \cdot 7 \%$.

The fatty acid composition of the duplicate portions was intended to reflect the distribution of individual fatty acids in the volunteers' diets and to act as a measure of compliance. This was achieved, as seen from the fatty acid compositional analysis. Differences in the major fatty acids of the palm-oil and control diets were obviously caused by the various products obtained for consumption from the 'shop' by the volunteers. For example, we have previously reported a higher content of shorter-chain fatty acids in the 
control dairy products (Sundram et al. 1990a). This is again reflected in the duplicateportion analysis wherein the sum of $\mathrm{C}_{10: 0}, \mathrm{C}_{12: 0}$ and $\mathrm{C}_{14: 0}$ fatty acids is almost $38 \%$ higher in the control duplicate portions than that of the palm-oil duplicate portions. Similarly, palmitic acid, a major component fatty acid of the palm-oil-based products, was significantly higher in duplicate portions of the palm-oil diet than that of the control diet. The content of stearic and oleic acids were almost reflections of the amounts of these fatty acids normally expected in palm oil (Sundram et al. 1990b). These fatty acid analyses, therefore, proved to be a useful compliance check on the fat consumption patterns of our volunteers, who consumed the specially-produced food products in a free-living environment.

The fatty acid composition of serum TG proved to be a reasonable compliance check on the diets consumed by our volunteers, when comparisons were made to the fatty acid composition of the duplicate portions. This observation is further reinforced since both serum and duplicate portions were sampled during each dietary period. A significant elevation in palmitic acid content in both serum TG and duplicate-portion fatty acids, as a result of the palm-oil diet, reflects adherence to this diet by our volunteers. This observation is further enhanced by our reported fatty acid composition of the palm-oil food products themselves (Sundram et al. 1990a), wherein a consistently higher palmitic acid content was evident. In the control duplicate portions a significantly higher level of 14:0, $16: 1(n-7), 17: 0$ and $20: 1(n-9)$ fatty acids was observed. These fatty acids are also significantly elevated in the serum TG of the volunteers during the control diet relative to the palm-oil diet. As further evidence of compliance, the SFA and $(n-6):(n-3)$ fatty acid ratio showed a similar tendency to be significantly elevated in both the serum TG and duplicate-portion fatty acids during the palm-oil diet.

Serum TC was essentially similar at the completion of both the palm-oil and control treatments. Nevertheless both IDL-C and LDL-C tended to be lower after the palm-oil treatment relative to the controls. Traditionally $\mathrm{LDL}$ is represented by the $\rho 201.006-1.063$ fraction. However, even after taking this into consideration, the sum of the IDL-C and LDL-C after the palm-oil treatment was still marginally lower than that of the control diet.

These observations seem contradictory to the findings of several workers (Laine et al. 1982; Baudet et al. 1984; Mattson \& Grundy, 1985; Grundy \& Vega, 1988) who reported significantly higher levels of both serum and LDL-C resulting from a palm-oil diet, high in palmitic acid. However, these comparisons were performed against dietary compositions that contained high amounts of either PUFA or MUFA. In one study (Bonanome \& Grundy, 1988) the serum cholesterol content was reported to be lower on a high-stearic acid diet compared with a palm-oil diet. Our study was performed in a population whose habitual $P: S$ ratio was $0 \cdot 43$. Maximal substitution with palm oil changed the $P: S$ ratio to 0.40 , while that of the control was 0.43 . In themselves these changes were minimal, but we observed a shift in the type of SFA contributed by these diets: the palm-oil diet had a significantly higher content of palmitic acid (11.7 v. $8.5 \mathrm{en} \%)$, whereas the control diet had higher levels of $\mathrm{C}_{12: 0}+\mathrm{C}_{14: 0}$ and $\mathrm{C}_{18: 0}$ fatty acids. Since stearic acid is considered neutral, the real comparison lies between $C_{12: 0}+C_{14: 0}$ and $C_{16: 0}$.

The findings of Keys et al. $(1965 a, b)$ and Hegsted et al. (1965) indicate that not all SFA raise cholesterol to the same extent. Bonanome \& Grundy (1988) confirmed earlier findings (Keys et al. 1965a,b) that stearic acid is neutral in its cholesterol-raising potential compared with palmitic acid. Therefore, the true cholesterol-raising effect of the SFA is constrained in fatty acids $C_{12: 0}, C_{14: 0}$ and $C_{16: 0}$. In the present study the palm-oil diet resulted in an increase of almost $3.2 \mathrm{en} \%$ in $\mathrm{C}_{16: 0}, 1.0$ en $\%$ reduction in $\mathrm{C}_{12: 0}+\mathrm{C}_{14: 0}$ and 0.7 en $\%$ reduction in $C_{18: 0}$ in comparison with the control diet (see Tables 2 and 3). Palmoil consumption did not significantly affect serum TC. If stearic acid is considered neutral, 
the cholesterol-modifying effect of the 1 en $\%$ decrease in $\mathrm{C}_{12: 0}+\mathrm{C}_{14: 0}$ was compensated by that of the $3 \cdot 2$ en $\%$ increase in $\mathrm{C}_{16: 0}$. On this assumption, the cholesterol-increasing effect of $\mathrm{C}_{16: 0}$ was about one-third that of $\mathrm{C}_{12: 0}+\mathrm{C}_{14: 0}$. This observation is in the same direction as the recent findings of Hayes et al. (1991) in non-human primates, wherein the hypercholesterolaemic effect of SFA was primarily due to $C_{12: 0}+C_{14: 0}$ and not to $C_{16: 0}$.

The diets in the present study revealed a modest difference $(66 \mathrm{mg} / \mathrm{d})$ in their cholesterol content. However, Hegsted et al. (1965) and Anderson et al. (1976) demonstrated that the effect of dietary $\mathrm{C}_{14: 0}$ and $\mathrm{C}_{16: 0}$ on serum cholesterol was independent of the cholesterol content in the diet. In addition, McNamara (1990) pointed out that the serum cholesterol response to changes in dietary cholesterol intake is negligible, and averages $0.05 \mathrm{mmol} / \mathrm{l}$ for each $100 \mathrm{mg} / \mathrm{d}$ change in dietary cholesterol intake. On this basis, the difference in dietary cholesterol intake between the palm-oil and control diets $(66 \mathrm{mg} / \mathrm{d})$ could be expected to account for a difference in serum cholesterol response equivalent to $0.03 \mathrm{mmol} / \mathrm{l}$. Therefore, the difference in dietary cholesterol in our diets would appear to be negligible.

HDL-C tended to be raised after the palm-oil diet in comparison with the control diet. This tendency occurred without a concurrent significant elevation in either serum TC or LDL-C. $\mathrm{HDL}_{3}-\mathrm{C}$ representing approximately $70 \%$ of the HDL-C in our subjects was not attered significantly by the diets. Epidemiological studies (Rhoads et al. 1976; Gordon et al. 1977) have established an inverse correlation between coronary heart disease and the concentration of HDL-C. Results by Miller et al. (1981) suggest that $\mathrm{HDL}_{2}-\mathrm{C}$ concentration may be a better reflection of this protective effect than those of $\mathrm{HDL}-\mathrm{C}$ or $\mathrm{HDL}_{3}-\mathrm{C}$. The significant increase in $\mathrm{HDL}_{2}-\mathrm{C}$ without compensatory increases in both serum $\mathrm{TC}$ and LDL-C, as observed during the palm-oil diet, is provocative especially since palm oil contains almost $50 \%$ of its fatty acid composition as saturates. The mechanism of this effect on the $\mathrm{HDL}_{2}$ subfraction needs to be investigated.

Miller et al. (1981) also reported that the best discriminator between subjects with severe coronary disease and those with minimal coronary disease was the $\mathrm{HDL}_{2}-\mathrm{C}$ : cholesterol content in the $\rho 1.019-1.063$ fraction, which also corresponds to our reported LDL-C measurements. Notably, the calculated $\mathrm{HDL}_{2}-\mathrm{C}: \mathrm{LDL}-\mathrm{C}$ ratio in the present study is higher on the palm-oil diet $(0 \cdot 120$ (SE 0.012)) than on the control diet $(0 \cdot 105$ (SE 0.010)), which was significant $\left(P_{2}=0.01\right)$. The calculated cholesterol ratios for $\mathrm{LDL}: \mathrm{HDL}_{2+3}$ and (IDL$+\mathrm{LDL}): \mathrm{HDL}_{2+3}$ were significantly lowered on the palm-oil diet. These lipoprotein ratios are good indicators of the atherogenic potential of the diet (Naito, 1985).

In the present study, serum TC following the palm-oil diet was comparable with that after the control diet, whereas a marginal decline in serum TG was observed. Furthermore, palm-oil feeding resulted in a tendency to lower cholesterol values in the IDL and LDL fractions. Similarly, TG in the IDL fraction tended to be lowered $\left(P_{2}=0.08\right)$, whereas the LDL-TG concentration was significantly lower after the palm-oil diet relative to the control diet. This overall trend, especially in relation to the IDL and LDL fractions which are considered atherogenic mediators (Tatami et al. 1981), indicates that the consumption of palm oil does not encourage a disposition to increasing the risk of atherosclerosis in normal healthy subjects.

The response of apolipoproteins to manipulations in the diet has been previously examined (Fisher et al. 1983; Zanni et al. 1987; Denke \& Breslow, 1988). There are, however, no reported values of apolipoproteins after a palm-oil diet. Our results demonstrate that palm-oil maximization in a Dutch-type diet causes a significant increase in apolipoprotein AI while reducing apolipoprotein B. This is in spite of the little change in the overall P:S fatty acid ratio between the palm-oil and control diets. These observations after the palm-oil diet lead to a significant reduction of the apolipoproteins $\mathrm{B}$ : AI ratio compared with the control diet. Mean apolipoprotein AI: AII ratio increased 
in volunteers consuming the palm-oil diet, which suggests that $H D L_{2}$ may have increased relative to $\mathrm{HDL}_{3}$. This is emphasized by our observation that $\mathrm{HDL}_{2}-\mathrm{C}$ in palm-oilconsuming volunteers was significantly increased relative to the control diet.

The present study indicates that when dietary palm oil, rich in palmitic acid $\left(\mathrm{C}_{16: 0}\right)$, replaced a substantial portion of the habitual fat content in a Dutch-type diet the serum TC and TG concentrations were unaffected, but the $\mathrm{LDL}: \mathrm{HDL}_{2+3}$ and apolipoprotein $\mathrm{B}: \mathrm{AI}$ ratios were favourably reduced. These changes may be related to the observed shift in the SFA ratio $\mathrm{C}_{16: 0}:\left(\mathrm{C}_{12: 0}+\mathrm{C}_{14: 0}\right)$ during the palm-oil diet. Nevertheless, the effect of minor components present in palm oil, although present in small quantities but having potent biological activity, cannot be ruled out. Specific studies must, therefore, be designed to evaluate these effects.

This work was supported by a research grant from the Palm Oil Research Institute of Malaysia (PORIM) and the Dutch Heart foundation. The authors thank Professor P. J. Brombacher, De Wever Ziekenuis, Heerlen, The Netherlands, for analyses of cholesterol and TG contents of serum and lipoprotein fractions, and Dr L. M. Havekes, Gaubius Institute, Leiden, The Netherlands, for measurements of serum apolipoproteins. In addition, the technical assistance of $\mathbf{J}$. Stegen is gratefully acknowledged. They finally thank A. Smook, T. Oude Nijhuis and P. Seuren for the dietary history interviews and M. Berndes for typing the manuscript.

\section{REFERENCES}

Alvers, J. J., Wahl, P. W., Cabana, V. G., Hazzard, W. R. \& Hoover, J. J. (1976). Quantitation of apolipoprotein AI of human plasma high density lipoprotein. Metabolism 25, 633-644.

AMA Council on Scientific Affairs (1983). Dietary and pharmacological therapy for the lipid risk factors: a council statement. Journal of the American Medical Association 250, 1873-1879.

Anderson, J. T., Grande, F. \& Keys, A. (1976). Independence of the effects of cholesterol and degree of saturation of fat in the diet on serum cholesterol in man. American Journal of Clinical Nutrition 29, 1784-1789.

Anon (1987). New findings on palm oil. Nutrition Review 45, 205-207.

Armitage P. \& Berry, G. (1987). Statistical Methods in Medical Research. Oxford: Blackwell.

Baudet, M. F., Dachet, C., Lasserre, M., Esteva, O. \& Jacotot, B. (1984). Modification in the composition and metabolic properties of human low density lipoproteins by different dietary fats. Journal of Lipid Research $\mathbf{2 5}$, $456-468$.

Bligh, E. G. \& Dyer, W. J. (1959). A rapid method for total lipid extraction and purification. Canadian Journal of Biochemistry and Physiology 37, 911-917.

Bonanome, A. \& Grundy, S. M. (1988). Effect of dietary stearic acid on plasma cholesterol and lipoprotein levels. New England Journal of Medicine 318, 1244-1248.

Bovenkamp, P. v. d. \& Katan, M. B. (1981). Cholesterol content of chicken skin. Journal of Food Science 46, 291.

Denke, M. A. \& Breslow, J. L. (1988). Effect of a low fat diet with and without intermittent saturated fat and cholesterol ingestion on plasma lipid, lipoprotein and apolipoprotein levels in normal volunteers. Journal of Lipid Research 29, 963-970.

Fisher, E. A., Blum, C. B., Zannis, V. I. \& Breslow, J. L. (1983). Independent effects of dietary saturated fat and cholesterol on plasma lipids, lipoproteins and apolipoprotein E. Journal of Lipid Research 24, 1039-1048.

Ginsberg, H. N., Barr, S. L., Gilbert, A., Karmally, W., Deckelbaum, R., Kaplan, K., Ramakrishnan, R., Holleran, S. \& Dell, R. B. (1990). Reduction of plasma cholesterol levels in normal men on an American Heart Association step 1 diet or a step 1 diet with added monounsaturated fat. New England Journal of Medicine 322 , $574-579$.

Gordon, T., Castelli, W. P., Hjortland, M. C., Kannel, W. B. \& Dawber, T. R. (1977). High density lipoprotein as a protective factor against coronary heart disease. American Journal of Medicine 62, 707-714.

Grande, F. (1962). Dog serum lipid responses to dietary fats differing in the chain length of the saturated fatty acids. Journal of Nutrition 76, 255-264.

Grundy, S. M. \& Vega, G. L. (1988). Plasma cholesterol responsiveness to saturated fatty acids. American Journal of Clinical Nutrition 47, 822-824.

Hashim, S. A., Artega, A. \& van Itallie, T. B. (1960). Effect of saturated medium chain triglyceride on serum lipids in man. Lancet i, 1105-1108.

Havekes, L. M., de Knijff, P., Beisiegel, U., Havinga, J., Smit, M. \& Klasen, E. (1987). A rapid micromethod for apolipoprotein E phenotyping directly in serum. Journal of Lipid Research 28, 455.463. 
Havekes, L. M., Hemmink, J. \& de Wit, E. (1981). Low-density-lipoprotein apoprotein B in plasma as measured by radial immunodiffusion and rocket immunoelectrophoresis. Clinical Chemistry 27, 1829-1833.

Hayes, K. C., Pronczuk, A., Lindsay, A. \& Diersen-Schade, D. (1991). Dietary saturated fatty acids (12:0, 14:0, 16:0) differ in their impact on plasma cholesterol and lipoproteins in non-human primates. American Journal of Clinical Nutrition 53, 491-498.

Hegsted, D. M., McGandy, R. B., Meyers, M. L. \& Stare, F. J. (1965). Quantitative effects of dietary fat on serum cholesterol in man. American Journal of Clinical Nutrition 27, 281-295.

Keys, A., Anderson, J. T. \& Grande, F. (1965a). Prediction of serum cholesterol responses of man to changes in fats in the diet. Lancet ii, 959966

Keys, A., Anderson, J. T. \& Grande, F. (1965b). Serum cholesterol responses to changes in diet. IV. Particular saturated fatty acids in the diet. Metabolism 14, 776-787.

Laine, C. W., Snodgrass, C. M., Dawson, E. A., Ener, M. A., Kuba, K. \& Frantz, I. D. Jr (1982). Lightly hydrogenated soya oil versus other vegetable oils as a lipid-lowering dietary constituent. American Journal of Clinical Nutrition 35, 683-690.

(1988). Manual for BECEL $L^{\mathbb{E}}$ Food Programme. Vlaardingen, The Netherlands: Unilever Research.

Mattson, F. H. \& Grundy, S. M. (1985). Comparison of effects of dietary saturated, monounsaturated and polyunsaturated fatty acids on plasma lipids and lipoproteins in man. Journal of Lipid Research 26, 194-202.

MeNamara, D. J. (1990). Dietary cholesterol: effects on lipid metabolism. Current Opinion in Lipidology 1, 18-22.

Mensink, R. P. \& Katan, M. B. (1989). Effect of a diet enriched with monounsaturated or polyunsaturated fatty acids on levels of low-density and high-density lipoprotein cholesterol in healthy women and men. New England Journal of Medicine 321, $436-441$.

Mensink, R. P. \& Katan, M. B. (1990). Effect of dietary trans fatty acids on high-density and low-density lipoprotein cholesterol levels in healthy subjects. New England Journal of Medicine 323, 439-445.

Mielke, S. (1987). The prospects for palm oil up to the year 2000. Oil World 30, 147-156.

Miller, N. E., Hammett, F., Saltissi, S., Rao, S., van Zeller, H., Coltart, J. \& Lewis, B. (1981). Relation of angiographically defined coronary artery disease to plasma lipoprotein subfractions and apolipoproteins. British Medical Journal 282, 1741-1744.

Ministry of Welfare, Health and Cultural Affairs and Ministry of Agriculture and Fisheries, The Netherlands (1988). Wat eet Nederland: Results of Food Consumption Survey 1987-1988. Zeist, The Netherlands: TNO CIVO Toxicology and Nutrition Inst.

Naito, H. K. (1985). The association of serum lipids, lipoproteins and apolipoproteins with coronary artery disease assessed by coronary arteriography. In Atherosclerosis [K. T. Lee, editor]. Annals of the New York Academy of Science 454, 230-238.

Pownall, H. J., Shepherd, J., Mantulin, W. W., Sklar, L. A. \& Gotto, A. M. Jr (1980). Effect of saturated and polyunsaturated fat diets on the composition and structure of human low density lipoproteins. Atherosclerosis 36, 299-314.

Qureshi, A. A., Burger, W. C., Peterson, D. M. \& Elson, C. E. (1986). The structure of an inhibitor of cholesterol biosynthesis isolated from barley. Journal of Biological Chemistry 261, 10544-10550.

Rand, M. L., Hennissen, A. A. H. M. \& Hornstra, G. (1986). Effects of dietary sunflowerseed oil and marine oil on membrane fluidity, arterial thrombosis and platelet responses in rats. Atherosclerosis 62, 267-276.

Rhoads, G. G., Gulbrandsen, C. L. \& Kagan, A. (1976). Serum lipoproteins and coronary heart disease in a population study of Hawaii Japanese men. New England Journal of Medicine 294, 293-298.

Schmitz, G. \& Assmann, G. (1982). Isolation of human serum HDL by zonal ultracentrifugation. Journal of Lipid Research 23, 903-910.

Spritz, N. \& Mishkel, M. A. (1969). Effects of dietary fats on plasma lipids and lipoproteins: an hypothesis for the lipid-lowering effect of unsaturated fatty acids. Journal of Clinical Investigation 48, 78-86.

Sundram, K., Hornstra, G. \& Schaap, J. E. (1990a). Characteristics of palm oil based food products developed for a nutritional intervention programme. Food Science and Nutrition 42F, 193-202.

Sundram, K., Khor, H. T. \& Ong, A. S. H. (1990 b). Effect of dietary palm oil and its fractions on rat plasma and high density lipoprotein lipids. Lipids 25, 187-193.

Tatami, R., Mabuchi, H., Ueda, K., Ueda, R., Haba, T., Kametani, T., Ito., Koizumi, J., Ohta, M., Miyamoto, S., Nakayama, A., Kanaya, H., Oiwake, H., Genda, A. \& Takeda, R. (1981). Intermediate-density lipoprotein and cholesterol-rich very low density lipoprotein in angiographically determined coronary artery disease. Circulation 64, 1174-1184.

Terpstra, A. H. M., Woodward, C. J. H. \& Sanchez-Muniz, F. J. (1981). Improved techniques for the separation of serum lipoproteins by density gradient ultracentrifugation: visualization by prestaining and rapid separation of serum lipoproteins from small volumes of serum. Annals of Biochemistry 111, 149-157.

Vega, G. L., Groszek, E., Wolf, R. \& Grundy, S. M. (1982). Influence of polyunsaturated fats on composition of plasma lipoproteins and apolipoproteins. Journal of Lipid Research 23, 811-822.

Zanni, E. E., Zannis, V. I., Blum, C. B., Herbert, P. N. \& Breslow, J. L. (1987). Effect of egg cholesterol and dietary fats on plasma lipids, lipoproteins and apolipoproteins of normal women consuming natural diets. Journal of Lipid Research 28, 518-527. 